\title{
Alternative insecticides for larval control of the dengue vector Aedes aegypti in Lao PDR: insecticide resistance and semi-field trial study
}

\author{
Sébastien Marcombe*, Somsanith Chonephetsarath, Phoutmany Thammavong and Paul T. Brey
}

\begin{abstract}
Background: The mosquito Aedes aegypti is the primary vector of several arboviruses, such as dengue, chikungunya and Zika, and represents a major public health problem in Southeast Asia. In Laos, where dengue is reemerging, several Ae. aegypti populations from the capital Vientiane have shown resistance to the organophosphate temephos, a commonly-used larvicide for public health interventions.

Methods: Here, we tested the insecticide susceptibility of a wild larval population of Ae. aegypti against Bacillus thuringiensis israelensis (Bti), diflubenzuron, pyriproxyfen and spinosad. Residual efficacies of Bti (VectobacWG ${ }^{\oplus}$ ), diflubenzuron (Killmos ${ }^{\circledast}$ ) and temephos (Abate ${ }^{\circledR}$ ) were then evaluated under simulated field conditions against the wild Ae. aegypti population.

Results: The larval bioassays showed that the wild Ae. aegypti strain was moderately resistant to temephos and spinosad (resistance ratio, $R R<5$ ) and fully susceptible to the other insecticides $(R R=1)$. The simulated field trial bioassays showed that all of the insecticides tested remained above the WHO acceptable larvicide threshold after 28 weeks.

Conclusions: These results suggest that Bti and diflubenzuron may be promising alternative larvicides for controlling dengue vectors in water-storage containers in Laos, especially against Ae. aegypti populations, in which resistance to temephos has been detected.
\end{abstract}

Keywords: Aedes aegypti, Vector control, Temephos, Bti, Diflubenzuron, Pyriproxyfen, Spinosad, IGR, Laos, Dengue

\section{Background}

Dengue is a vector-borne disease of public health importance in tropical and temperate regions of the world, with approximately $40 \%$ of the global population at risk. In Southeast Asia, dengue is threatening more than 1.3 billion people, representing $52 \%$ of the at-risk global population, and outbreaks have been occurring regularly across the region for several decades. In Laos, dengue is reemerging; the most important recent outbreak was in 2013 when 44,098 estimated cases were reported, including 98 deaths. As of October 2017, more than 9200 cases have been reported in Laos and the 2017 epidemic is still ongoing [1]. Since there is still no specific medication or

\footnotetext{
* Correspondence: s.marcombe@pasteur.la

Institut Pasteur du Laos, Ministry of Health, Vientiane, Lao PDR
}

effective vaccine available for dengue, control of the disease is mostly focused on targeting the vectors, Aedes aegypti and Aedes albopictus [2], by reducing mosquito densities through: (i) the elimination or protection of the potential breeding sites [3]; (ii) biological control using of larvae predators, such as small fishes or copepods [46], or entomopathogenic bacteria, such as Bacillus thuringiensis var. israelensis (Bti) [7]; or (iii) chemical control methods using insecticides for larval and adult mosquito control [3].

Despite the organized efforts to promote community participation in the dengue control programme since the 1990's [8, 9], Laos continues to face challenges addressing this important public health issue transmitted by Aedes mosquitoes. During dengue epidemics, dengue

(c) The Author(s). 2018 Open Access This article is distributed under the terms of the Creative Commons Attribution 4.0 International License (http://creativecommons.org/licenses/by/4.0/), which permits unrestricted use, distribution, and 
control programmes rely on the use of pyrethroid insecticides (e.g. permethrin and deltamethrin) to reduce adult mosquitoes, but this method is not consistent nor fully efficient due to the limited number of qualified vector control personnel and the low budget allocated towards mosquito control. Therefore, Laos has relied on the use of the insecticide temephos (Abate ${ }^{\circ}$ formulation) to reduce Ae. aegypti or Ae. albopictus larvae. This insecticide formulation is used to treat large water containers and is distributed throughout the country in places where dengue cases are reported, or as an active measure to treat known breeding sites that cannot be removed or protected.

It is possible that temephos resistance has spread in the country, as the insecticide has been used routinely since 1987 [8] and several bordering countries of Laos (Cambodia, Thailand and Vietnam) have reported temephos-resistant Ae. aegypti mosquitoes [10-13]. Laos vector control teams regularly report the inefficacy of the Abate ${ }^{\circ}$ sachets in treated habitats; recent studies in Laos have shown resistance or reduced susceptibility to temephos in Ae. aegypti and Ae. albopictus populations from several provinces and Vientiane capital (Marcombe, personal communication), the most dengueafflicted foci in the country [14]. Moreover, temephos continues to be under international scrutiny and deregulation for its toxicity against aquatic and non-target organisms [15]. Public health officials and scientists from around the world agree that new strategies in general, and new larvicides more specifically, are urgently needed to implement effective vector control operations in the field to combat dengue. In developing countries such as Laos, these new insecticides have to be cost-effective and environmentally friendly, particularly for the non-target organisms. The development of specific insecticide classes for mosquito control has been limited in previous decades, but new alternatives, primarily originating from the agricultural market, show promise in controlling Aedes mosquitoes [16].

The bacterial insecticide Bti represents a safe and efficient larvicide for mosquito control because of its fast killing effect and good toxicological profile [17]. After ingestion by larvae, Bti produce, by sporulation, solid parasporal crystal composed of insecticidal toxins (Cry and Cyt families) that have different modes of action but both result in disrupting the osmotic balance of the midgut cells of the mosquito larvae. Schnepf et al. [18] and Lacey et al. [17] described in detail the complexity of the mode of action of these Cyt and Cry toxin families. Diflubenzuron is an insect growth regulator (IGR) that disrupts chitin synthesis and deposition in mosquitoes, and has showed promising efficacy against several mosquito species, including Ae. aegypti [19-23]. Pyriproxyfen is a juvenile hormone mimic IGR that suppresses embryogenesis, metamorphosis and adult emergence in insects [20]. Pyriproxyfen showed interesting vector control properties against Aedes spp. in auto-dissemination studies [21, 22]. Spinosad is a bioinsecticide belonging to the naturalyte class, which are based on metabolites derived from the actynomycetale Saccharopolyspora spinosa (spinosin A and D) [23]. Spinosad acts on both the nicotinic acetylcholine and the $\gamma$-aminobutyric acid (GABA) receptors, causing paralysis and death because of increased excitation of the insect's nervous system [24]. This insecticide has a favorable profile with low environmental persistence and low toxicity to non-target insects and fish $[25,26]$. The larvicides cited above have different modes of action compared to temephos, and therefore represent interesting compounds for the management of insecticide resistance (IR) in Ae. aegypti populations in Laos. They are all recommended by the World Health Organization (WHO) for use as vector control in drinking water sources and containers, hence they are safe to humans [27-30].

In order to provide information on alternative insecticides to the vector control teams in Laos, we studied the resistance levels of one Ae aegypti population from Vientiane (IPL strain) against Bti, diflubenzuron, pyriproxyfen and spinosad. We also evaluated the residual efficacy of Bti, diflubenzuron and temephos against the wild IPL strain in simulated field trials. Pyriproxyfen and spinosad were not tested because of delivery delays.

\section{Methods}

\section{Mosquito strains}

Two strains of Ae. aegypti were used for the laboratory and semi-field trials. The USDA strain originating from Florida, USA, maintained in colony for decades, and obtained from Kasetsart University (Faculty of Agriculture, Entomology Department), was used as the insecticide susceptible reference strain for the larval bioassays. This strain is free of any insecticide resistance mechanisms (e.g. knock-down and enzymatic resistance mechanisms). The second strain, an Ae. aegypti colony (IPL strain) was established from wild, field-caught mosquito larvae collected from ovitraps placed at the Institut Pasteur du Laos (IPL) in the Sisattanak district of Vientiane capital in Kao-gnot village $\left(17.962684^{\circ} \mathrm{N}, 102.615035^{\circ} \mathrm{E}\right)$. Female adults obtained from the F0 generation were blood-fed on quail (Coturnix japonica) and their F1 or F2 progenies were used for the larval bioassays and simulated-field condition bioassays.

\section{Laboratory evaluation of insecticide resistance}

Larval bioassays were carried out using technical grades of temephos, Bti, diflubenzuron, spinosad and pyriproxyfen, according to WHO guidelines [31]. These insecticides were purchased from Sigma-Aldrich (Singapore, 
Singapore), except for Bti which was purchased from Valent BioScience (Libertyville, IL, USA). The class name, the mode of action, and the active ingredient purity of each insecticide are given in Table 1. Bioassays were performed using late third- and early fourth-instar larvae of the field strains. For each bioassay, larvae of each strain were transferred to cups containing $99 \mathrm{ml}$ of distilled water and $1 \mathrm{ml}$ of the insecticide tested at the desired concentration. Five cups per concentration (25 larvae per cup) and 5 to 8 concentrations in the activity range of each insecticide were diluted in ethanol, except for Bti, which was diluted in distilled water. Control treatments consisted of the addition of $1 \mathrm{ml}$ of ethanol to $99 \mathrm{ml}$ of water (distilled water for Bti assays). For each insecticide, three replicates were implemented. Larval mortality was recorded after an exposure of $24 \mathrm{~h}$ to temephos, spinosad and Bti. Because of the delayed action of diflubenzuron and pyriproxyfen, larval and adult mortality was assessed every day until emergence. In these cases, larvae were fed with dry cat food at a concentration of $100 \mathrm{mg} / \mathrm{l}$ and dead larvae were removed daily, as dead larvae may contribute to mortality. For each bioassay, temperature was maintained at $27{ }^{\circ} \mathrm{C}$, with a 12-h light: 12-h dark photoperiod.

\section{Simulated field trial}

The trial was carried out in Vientiane, Laos between October 2014 and May 2015, on the premises of the IPL. The effects of temephos $\left(1 \mathrm{mg} / \mathrm{l}\right.$, Abate ${ }^{\circ}$, Bangkok, Thailand), diflubenzuron ( $0.25 \mathrm{mg} / \mathrm{l}$, Killmos ${ }^{\circ}$, Bangkok, Thailand) and Bti (8mg/l, Vectobac, Libertyville, USA) formulations were evaluated and compared against $A e$. aegypti larvae from IPL strain at the dosage recommended by the WHO or the manufacturers for the control of mosquito larvae (Table 1). Blue plastic containers with a capacity of $200 \mathrm{l}$ were used because they are a common container for water storage in Vientiane City and have been shown to be an important productive breeding habitat for Ae. aegypti (Marcombe, personal communication). These drums were filled up with $175 \mathrm{l}$ of domestic water then covered with a mosquito net to prevent oviposition by wild female mosquitoes in the area and escape by adult mosquitoes introduced as larvae prior to counting. The containers were placed under a shelter to prevent direct exposure to rain and sunlight. Twelve containers (three replicates per insecticide) were allocated to insecticides at random. Three were left untreated and used as a control. Groups of 100 third-instar larvae of the F1 generation of the IPL strain were added to each container with $1 \mathrm{~g}$ of food (dry cat food) at time 0 , and then every 10 days. The containers were replenished every 10 days to maintain the initial level of water. Emerging adults were collected from each container by using electric aspirators and then stored at $-80{ }^{\circ} \mathrm{C}$. Temperature and $\mathrm{pH}$ were checked every 10 days with a portable tester to detect any differences between replicates and/or treatments. External temperature and humidity were recorded by using a meteorological unit.

\section{Statistical analysis}

For the determination of the intrinsic activity of each larvicide, three replicates with larvae from different rearing batches were made at different periods and the results were pooled for analysis $(n=300$ larvae per dose). According to the WHO guidelines [31], test with control mortality $>5 \%$ have to be corrected using Abbott's formula [32] and tests with control mortality $>20 \%$ have to be discarded. Results were analyzed using the log-probit method of Finney [33] using the Log dose Probit software (LdP) Line (Ehabsoft, Cairo, Egypt) to estimate the slope of regression lines and determine the 50\% and 95\% lethal concentration $\left(\mathrm{LC}_{50}\right.$ and $\mathrm{LC}_{95}$, respectively) with 95\% confidence intervals (CIs). The USDA and IPL strains were considered to have different susceptibilities to a given insecticides when their resistance ratio (RR) between their $\mathrm{LC}_{50}$ or $\mathrm{LC}_{95}$ (resistance ratio, $\mathrm{RR}_{50}$ or $\mathrm{RR}_{95}$ ) had CIs excluding the value of 1 . Following the WHO criteria, the IPL strain was considered resistant if the $R_{50}$ is over 10 , moderately resistant with a $R R_{50}$ between 2 and 10 and susceptible if the $R R_{50}$ is under 2 [31].

Regarding the simulated field trial, emergence inhibition rates (\% EI) and 95\% CIs were calculated for the average of the three replicates per insecticide according to the formula:

Table 1 Description of the insecticides used for the larval bioassays and the semi-field test

\begin{tabular}{|c|c|c|c|c|}
\hline Insecticide & Class group & Mode of action & $\begin{array}{l}\text { Larval bioassay, active } \\
\text { ingredient (\%) }\end{array}$ & $\begin{array}{l}\text { Formulation use for the simulated } \\
\text { test (Dose) }\end{array}$ \\
\hline Temephos & Organophosphate & Acetylcholinesterase inhibitor & 95.6 & Granules (1 mg/l) \\
\hline $\begin{array}{l}\text { Bacillus thuringiensis israelensis } \\
\text { strain } \mathrm{H} 14\end{array}$ & Bacterial larvicide & Cell membrane destruction & 37.4 (3000 ITU/mg) & Water dispersible granules (8 mg/l) \\
\hline Diflubenzuron & Insect growth regulator & Chitin biosynthesis inhibitor & 98.1 & Tablets (0.25 mg/l) \\
\hline Pyriproxyfen & Insect growth regulator & Juvenile hormone mimics & 99.10 & Not tested \\
\hline Spinosad & Naturalyte & Nicotinic acetylcholine receptors & 97.6 & Not tested \\
\hline
\end{tabular}




$$
\% E I=\left(\frac{C-T}{C}\right) \times 100
$$

where $\mathrm{C}$ is the emergence in the control and $\mathrm{T}$ is the emergence in the treated container at the same time period. For each formulation, curves were presented until the \% EI decreased to $<80 \%$, which corresponded to the threshold generally considered for reapplication of the treatment [31].

\section{Results}

\section{Insecticide resistance larval bioassays}

Results of the larval bioassays performed on the Ae. aegypti susceptible strain (USDA) and the wild strain (IPL) are shown in the Table 2. There was no control mortality over $5 \%$ so no correction with Abbot's formula was needed. The IPL strain was fully susceptible to the insecticides $B t i$, diflubenzuron and pyriproxyfen with $\mathrm{RR}_{50}$ of $0.84,1.1$ and 0.2 , respectively. The IPL strain was also susceptible to both temephos and spinosad but showed higher $R_{50}$ 's between $2-5$. The two IGRs (pyriproxyfen and diflubenzuron) had the highest insecticidal efficacy against the wild IPL strain, with an $\mathrm{LC}_{50}$ below $2 \mu \mathrm{g} / \mathrm{l}$, compared to temephos, Bti and spinosad with an $\mathrm{LC}_{50}$ of $6.6,11.8$ and $69 \mu \mathrm{g} / \mathrm{l}$, respectively.

\section{Semi-field trial experiment}

All treatments were effective (EI $>80 \%$ ) for at least 22 weeks and temephos had the best efficacy of all treatments with 96\% EI (4\% emergence) after 28 weeks (Fig. 1). Twenty-eight weeks after the treatments, the average \% EI in the containers treated with $B t i$ was less than $80 \%$, which is the limit recommended for a new treatment in field conditions. This threshold was exceeded in the containers treated with diflubenzuron after 24 weeks, but went back over $80 \%$ EI the week after, and dropping below $80 \%$ EI again at 28 weeks. The dramatic decrease of emergence in the control containers, dropping from $80 \%$ to $40 \%$ between T110 and T150, corresponds to an increasing temperature inside the containers during the same period (Fig. 2). During this period, the temperatures inside the containers rose from $22{ }^{\circ} \mathrm{C}$ to almost $30{ }^{\circ} \mathrm{C}$. This event may have had consequences on the treated containers, delaying the increase of emergence for a few weeks. During the experiment, the average $\mathrm{pH}$ measured in the containers remained between 7.6- 9.2 (Fig. 2).

\section{Discussion}

The objectives of this study were to evaluate candidate insecticides and to validate them under simulated field conditions. The specific modes of action of these insecticides represent valuable tools for future use in public health programmes in Laos. The larval bioassays showed that the wild IPL strain was fully susceptible against Bti, diflubenzuron and pyriproxyfen, and tolerant to spinosad. The ranges of insecticidal activities measured in our study were comparable with other studies tested against Ae. aegypti in several countries [34-39]. The absence of resistance against these insecticides by the wild IPL strain is encouraging, and anticipated, since these insecticides have never been used in Laos for vector control operations.

The insecticide temephos had the best residual efficacy compared to the other insecticides. This can be explained by the dose used to treat the containers, which is much higher than the $\mathrm{LC}_{95}$ of the wild IPL strain, but the efficacy would probably have not been as long against the Laos resistant strains found throughout the country. The synergistic effect of the Bti toxins together may explain why no resistance has been detected yet in areas where this bio-insecticide has been used routinely

Table 2 Resistance status of Aedes aegypti (USDA and IPL strains) against temephos and potential alternative insecticides. Numbers in bold correspond to a resistance ratio (RR) statistically different from 1. RR between 2 and 10 show a moderate resistance to the insecticide according to $\mathrm{WHO}$ criteria

\begin{tabular}{|c|c|c|c|c|c|c|c|c|c|}
\hline$\underline{\text { Larvicide }}$ & Strain & No. of larvae & $\mathrm{LC}_{50}(95 \% \mathrm{Cl})(\mu \mathrm{g} / \mathrm{l})$ & $\mathrm{LC}_{95}(95 \% \mathrm{Cl})(\mu \mathrm{g} / \mathrm{l})$ & $\mathrm{RR}_{50}$ & $\mathrm{RR}_{95}$ & $x^{2}$ & $P$ & Slope \pm SE \\
\hline \multirow[t]{2}{*}{ Bti } & USDA & 1501 & $14(12-21)$ & $54(31-199)$ & - & - & 0.2 & 0.89 & $2.8 \pm 0.6$ \\
\hline & IPL & 1600 & $11.8(11.3-12.3)$ & $21(19-23)$ & 0.8 & 0.4 & 5.5 & 0.24 & $6.6 \pm 0.5$ \\
\hline \multirow[t]{2}{*}{ Diflubenzuron } & USDA & 1500 & $1.7(1.5-1.8)$ & $5.6(4.6-7.2)$ & - & - & 8.5 & 0.075 & $3.1 \pm 0.3$ \\
\hline & $\mathrm{IPL}$ & 804 & $1.8(1.4-2.1)$ & $4.1(3.8-6.8)$ & 1.1 & 0.7 & 20.0 & 0.0005 & $4.6 \pm 0.3$ \\
\hline \multirow[t]{2}{*}{ Pyriproxyfen } & USDA & 1500 & $0.086(0.05-0.1)$ & $0.049(0.03-0.06)$ & - & - & 4.4 & 0.11 & $1.4 \pm 0.3$ \\
\hline & $\mathrm{IPL}$ & 699 & $0.019(0.017-0.022)$ & $0.098(0.074-0.12)$ & 0.2 & 2.0 & 7.6 & 0.055 & $2.4 \pm 0.2$ \\
\hline \multirow[t]{2}{*}{ Spinosad } & USDA & 1500 & $14(12-19)$ & $40(26-96)$ & - & - & 0.4 & 0.79 & $3.6 \pm 0.3$ \\
\hline & $\mathrm{IPL}$ & 1472 & $69(62-77)$ & $206(170-270)$ & 4.9 & 5.2 & 3.4 & 0.18 & $3.4 \pm 0.3$ \\
\hline \multirow[t]{2}{*}{ Temephos } & USDA & 1250 & $2.9(2.7-3.1)$ & $6.6(5.8-7.6)$ & - & - & 3.7 & 0.59 & $4.6 \pm 0.3$ \\
\hline & IPL & 2600 & $6.6(6.2-6.9)$ & $11.6(10.5-13.5)$ & 2.3 & 1.8 & 5.3 & 0.07 & $6.6 \pm 0.5$ \\
\hline
\end{tabular}

Abbreviations: USDA Susceptible reference strain, IPL Wild strain, LC Lethal concentration, CI Confidence interval, RR Resistance ratio = LC of IPL/LC of USDA strain; SE Standard error 


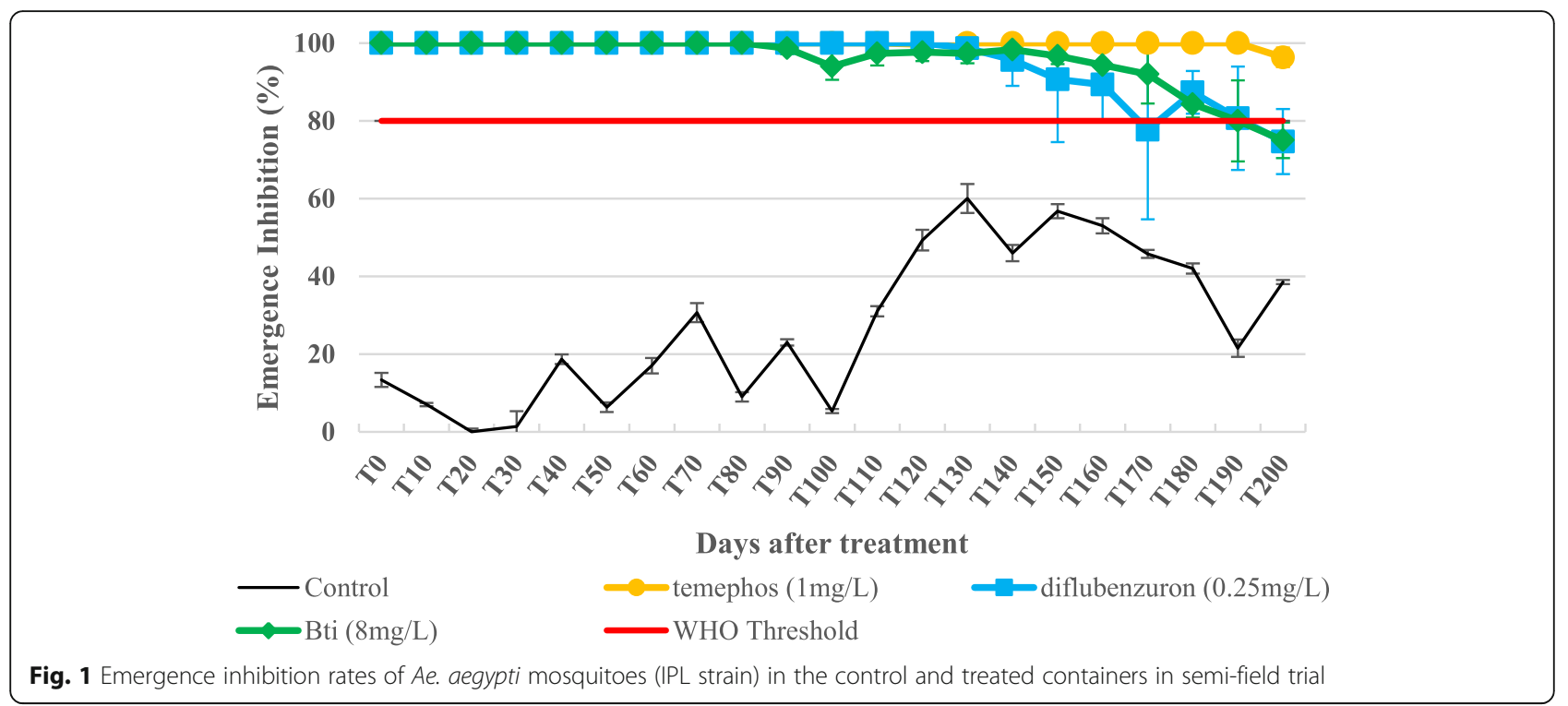

for years [17, 39], theoretically making it a good alternative for Aedes control [34, 35]. The IGRs diflubenzuron and pyriproxyfen represent other potential alternatives to decrease local mosquito population abundance. However, the use of IGRs should be implemented with caution, with recent studies showing evidence of resistance to IGRs developing in Aedes sp. field populations [34, 39-41]. Despite no cross-resistance between IGRs and conventional insecticides demonstrated in Aedes mosquitoes, Yunta et al. [42] showed the involvement of P450 monooxygenases (i.e. insecticide detoxifying enzymes) in the cross-resistance mechanisms between pyriproxyfen and pyrethroids in the malaria vector Anopheles gambiae in Africa. Importantly, overexpressed P450s genes are responsible for pyrethroid resistance in Ae. aegypti mosquitoes [43] and have been reported worldwide [12, 44]. A recent biochemical study showed that several pyrethroid resistant Ae. aegypti populations from Laos had higher levels of P450s enzymes compared to the susceptible reference strain USDA. The tolerance of the IPL strain to spinosad (RR > 5) could be explained by the differences in genetic background between the wild and susceptible strains, the later having been colonized for decades with no exposure to insecticides or other xenobiotics [45]. Furthermore, the spinosins (A and D) act on different targets of the mosquito nervous system, lowering the occurrence of cross-resistance with conventional insecticides [38].

The new candidate insecticides Bti and diflubenzuron showed equal efficacy as temephos for up to 7 months

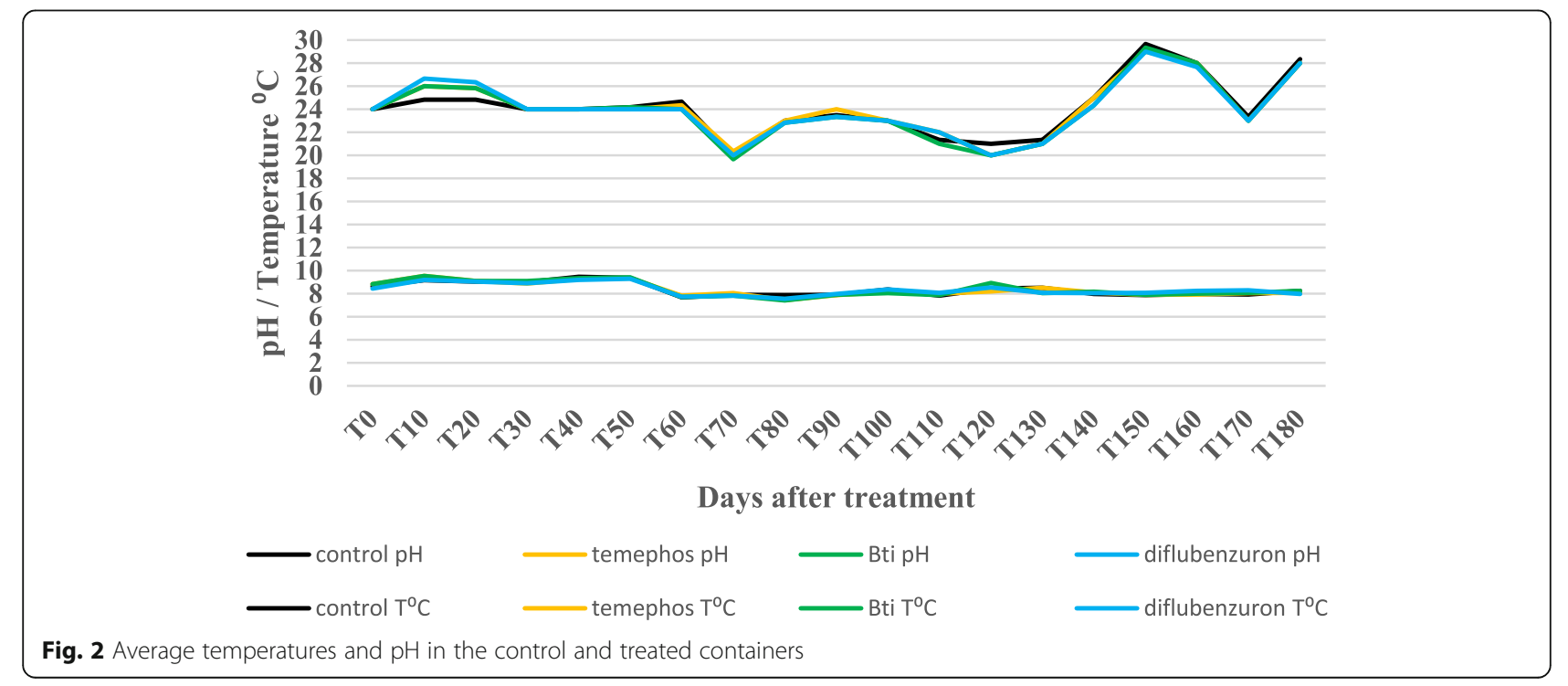


in simulated field conditions. The result of Bti measured is correlated to a study implemented in similar conditions in the Martinique (Caribbean) [34]. However, in that study, the temephos efficacy (EI > 80\%) was 20 weeks, compared to 28 weeks in Laos. This can be explained by the high temephos resistance levels measured in this Ae. aegypti population compared to the IPL strain (i.e. $\mathrm{RR}_{95}$ of 175 and 1.76, respectively). Other simulated field studies measured the efficacy of different diflubenzuron formulations (granular sand and tablet formulations) and the results showed EI $>80 \%$ for more than 23 weeks against Ae. aegypti $[46,47]$, making this insecticide a good candidate for control. The rotational or mosaic use of Bti, diflubenzuron and temephos in Laos may be a good strategy to prevent or limit insecticide resistance development.

$B t i$ is extensively used for the control of mosquito species [48], but compared to other insecticides, such as temephos and the alternatives diflubenzuron and spinosad, it has short-term residual efficacy in natural conditions against Ae. aegypti. In large-scale field trials implemented in Martinique and the Philippines, Bti formulations used to treat large water containers were effective only 3-4 weeks after treatments, while spinosad and diflubenzuron were effective for 16 weeks [34, 49]. Thavara et al. [47] also showed a good residual activity of diflubenzuron under field conditions, with 23 weeks efficacy. Marcombe et al. [34] showed that, similar to Bti, pyriproxyfen lost its efficacy after four weeks post-treatment. The short residual activity of an insecticide is a concern for their use in dengue control programmes because operators have to repeat the treatments regularly [50]. The use of a combination of two insecticides is a way to increase the efficacy of the treatments. For example, combination of Bti and Lysinibacillus sphaericus (Lsph) compensates for the low residual efficacy of the former by the synergistic effect of their toxins. Another study showed the synergistic effect of spinosad and pyriproxyfen in mixture against Ae. aegypti in a large-scale field trial [51]. The residual efficacy of the combination was increased by 1.5 months, in comparison of the insecticides alone. Recent laboratory studies showed that octopamine receptor agonists (OR agonists) increased the potency of IGRs against Ae. aegypti [52]. The use of OR agonists in combination with IGR is a promising tool for vector control but more studies have to be implemented to understand the synergistic mechanisms involved.

The good residual efficacy of the diflubenzuron and $B t i$ formulations is encouraging, however, the results observed in well-controlled conditions has to be taken with caution and cannot be used to predict the performance of the formulations under field conditions. Indeed, in real treatment conditions, the direct exposure to sunlight, rain and organic matter and water exchange practices can significantly reduce the residual efficacy of an insecticide $[34,47,53]$. Despite the relatively good residual activity of the temephos formulation observed against the wild IPL strain, Aedes control teams in Laos continue to report temephos use failures in treated containers. These examples emphasize the need for alternatives to temephos, and the continued use of this insecticide in Laos should be reconsidered, as it will certainly lead to fully resistant Aedes populations.

\section{Conclusions}

This study measured the IR status of a wild Ae. aegypti population from Vientiane, under laboratory conditions, against the conventional insecticide temephos and candidate larvicidal alternatives to better inform Laotian dengue control teams. Insecticide resistance bioassays showed that the wild IPL field strain was susceptible to $B t i$, diflubenzuron and pyriproxyfen, making them good alternative insecticides to temephos for vector control. Temephos, Bti and diflubenzuron showed good residual efficacy against the wild IPL strain in widely used plastic water container habitats in simulated, controlled field trials; however, a more comprehensive study to measure the real efficacy of these alternatives in the environmental and socio-economic conditions of Laos should be pursued. If these insecticides are to be used in the future in Laos, constant monitoring of the insecticide resistance status of Aedes populations is recommended. Furthermore, because of the increasing importance of these alternative insecticides for vector control, the study of the insecticide resistance mechanisms in mosquitoes against alternatives should not be neglected [44].

\section{Abbreviations}

GABA: $\gamma$-aminobutyric acid; Bti: Bacillus thuringiensis israelensis; $\mathrm{Cl}$ : Confidence interval; El: Emergence inhibition; IGR: Insect growth regulator; IPL: Institut Pasteur du Laos; IR: Insecticide resistance; LC: Lethal concentration;

Lsph: Lysinibacillus sphaericus; OR: Octopamine receptor; RR: Resistance ratio; SE: Standard error

\section{Acknowledgments}

We thank the staff of the entomology department of the Institut Pasteur du Laos for the mosquito rearing and preparation of the larval bioassays and simulated field experiment tests (Khanthalat Khounsombat, Somphat Nilaxay, Abigail Jordan, Boutsady Somphong and Nothasin Phommavan).

\section{Availability of data and materials \\ The dataset supporting the conclusions of this article is included within the} article.

\section{Financial support}

This work was supported by the Institut Pasteur du Laos.

\section{Authors' contributions}

Conceived and designed the experiments: SM and PTB. Performed the experiments: SM, SC and PT. Analyzed the data: SM. Contributed reagents/ materials/analysis tools: SM. Wrote the paper: SM and PTB. All authors read and approved the final manuscript.

Ethics approval and consent to participate

No ethical authorization and consent to participate was needed for this study. 


\section{Consent for publication}

Not applicable.

\section{Competing interests}

The authors declare that they have no competing interests.

\section{Publisher's Note}

Springer Nature remains neutral with regard to jurisdictional claims in published maps and institutional affiliations.

Received: 19 July 2018 Accepted: 6 November 2018 Published online: 03 December 2018

\section{References}

1. WHO. Dengue biweekly report 20171010. 2017. Geneva: World Health Organization; 2017. http://origin.wpro.who.int/emerging_diseases/dengue_ biweekly_report_20171219.pdf

2. WHO. A global brief on vector-borne diseases. Geneva: World Health Organization; 2014.

3. WHO. Special programme for research and training in tropical diseases. In: Dengue guidelines for diagnosis, treatment, prevention and control. Geneva: World Health Organization; 2009.

4. Seng CM, Setha T, Nealon J, Socheat D, Chantha N, Nathan MB. Community-based use of the larvivorous fish Poecilia reticulata to control the dengue vector Aedes aegypti in domestic water storage containers in rural Cambodia. J Vector Ecol. 2008;33:139-44.

5. Julo-Réminiac J-E, Tran PV, Nguyen YT, Nguyen HT, Vu DB, Hoang DM, et al. Validation of Mesocyclops (Copepoda) and community participation as an effective combination for dengue control in northern Vietnam. Field Actions Sci Rep. 2014;7:3759. https://journals.openedition.org/factsreports/3759.

6. Jennings $C D$, Phommasak B, Sourignadeth B, Kay BH. Aedes aegypti control in the Lao People's Democratic Republic, with reference to copepods. Am Soc Trop Med Hyg. 1995;53:324-30

7. Rapley LP, Ritchie SA, Benjamin S. Bacillus thuringiensis var. israelensis (Bti) provides residual control of Aedes aegypti in small containers. Am J Trop Med Hyg. 2010;82:1053-9.

8. Phommasak B. Dengue haemmorrhagic fever control activities in Vientiane. Vientiane: Health and Social Welfare Services; 1990.

9. Nambanya S. Status of dengue fever/dengue haemorrhagic fever in Lao People's Democratic Republic. Dengue Bull. 1997;21:115-6.

10. Jirakanjanakit N, Rongnoparut $P$, Saengtharatip $S$, Chareonviriyaphap T, Duchon S, Bellec C, et al. Insecticide susceptible/resistance status in Aedes (Stegomyia) aegypti and Aedes (Stegomyia) albopictus (Diptera: Culicidae) in Thailand during 2003-2005. J Econ Entomol. 2007;100:545-50.

11. Khun S, Manderson LH. Abate distribution and dengue control in rural Cambodia. Acta Trop. 2007;101:139-46.

12. Ranson H, Burhani J, Lumjuan N, Black WC IV. Insecticide resistance in dengue vectors. TropIKA.net [serial on the Internet]. 2010 Mar [cited 2018 Nov 11]; 1(1). Available from: http://journal.tropika.net/scielo.php?script=sci_ arttext\&pid=\$2078-86062010000100003\&lng=en.

13. Chareonviriyaphap T, Bangs MJ, Suwonkerd W, Kongmee M, Corbel V, Ngoen-Klan R. Review of insecticide resistance and behavioral avoidance of vectors of human diseases in Thailand. Parasit Vectors. 2013;6:280.

14. Lao M, Caro V, Thiberge J-M, Bounmany P, Vongpayloth K, Buchy P, et al. Co-circulation of dengue virus type 3 genotypes in Vientiane Capital, Lao PDR. PLoS One. 2014;9:e115569.

15. Directive $98 / 8 /$ EC of the European Parliament and of the Council of 16 February 1998 concerning the placing of biocidal products on the market in the Official Journal of the European Communities.1998. https://eur-lex.europa.eu/legal-content/EN/ALL/?uri=celex:31998L0008. Accessed 29 Oct 2018.

16. Bill and Melinda Gates Foundation. Market assessment for public health pesticide products. In: Malaria forum final report. Washington, DC: Bill and Melinda Gates Foundation; 2007. https://docs.gatesfoundation.org/ documents/malariaforumreport.pdf. Accessed 29 Oct 2018.

17. Lacey LA. Bacillus thuringiensis serovariety israelensis and Bacillus sphaericus for mosquito control. J Am Mosq Control Assoc. 2007:23:133-63.

18. Schnepf E, Crickmore N, Van Rie J, Lereclus D, Baum J, Feitelson J, et al. Bacillus thuringiensis and its pesticidal crystal proteins. Microbiol Mol Biol Rev. 1998;62:775-806.
19. Matsumura F. Studies on the action mechanism of benzoylurea insecticides to inhibit the process of chitin synthesis in insects: a review on the status of research activities in the past, the present and the future prospects. Pestic Biochem Physiol. 2010;97:133-9.

20. Hirano M, Hatakoshi M, Kawada H, Takimoto Y. Pyriproxyfen and other juvenile hormone analogues. Rev Toxicol. 1998;2:357-94.

21. Devine GJ, Perea EZ, Killeen GF, Stancil JD, Clark SJ, Morrison AC. Using adult mosquitoes to transfer insecticides to Aedes aegypti larval habitats. Proc Natl Acad Sci USA. 2009;106:11530-4.

22. Chandel K, Suman DS, Wang Y, Unlu I, Williges E, Williams GM, et al. Targeting a hidden enemy: pyriproxyfen autodissemination strategy for the control of the container mosquito Aedes albopictus in cryptic habitats. PLoS Negl Trop Dis. 2016;10:e0005235.

23. Copping LG, Menn JJ. Biopesticides: a review of their action, applications and efficacy. Pest Manag Sci. 2000:56:651-76.

24. Su T. Resistance and its management to microbial and insect growth regulator larvicides in mosquitoes. In: Trdan S, editor. Insecticides Resistance. Rijeca: InTech; 2016. http://www.intechopen.com/books/insecticidesresistance/resistance-and-its-management-to-microbial-and-insect-growthregulator-larvicides-in-mosquitoes.

25. Williams T, Valle J, Viñuela E. Is the naturally derived insecticide Spinosad compatible with insect natural enemies? Biocontrol Sci Technol. 2003; 13:459-75.

26. Pereira BB, Caixeta ES, Freitas PC, Santos VSV, Limongi JE, de Campos Júnior EO, et al. Toxicological assessment of spinosad: implications for integrated control of Aedes aegypti using larvicides and larvivorous fish. J Toxicol Environ Health A. 2016;79:477-81.

27. WHO. Report of the Seventh WHOPES Working Goup Meeting, WHO/HQ, Geneva, December 2-4, 2003, Review of Vectobac WG, Permanet, Gokilath-S 5EC. Document WHO/CDS/WHOPES/2004.8. Geneva: World Health Organization; 2004.

28. WHO. Diflubenzuron in drinking-water: use for vector control in drinkingwater sources and containers. Document WHO/HSE/AMR/08.03/6. Geneva: World Health Organization; 2008.

29. WHO. Pyriproxyfen in drinking-water: use for vector control in drinkingwater sources and containers. Document WHO/HSE/AMR/08.03/9. Geneva: World Health Organization; 2008

30. WHO. Spinosad DT in drinking-water: use for vector control in drinkingwater sources and containers. Document WHO/HSE/WSH/10.01/12. Geneva: World Health Organization; 2010.

31. WHO. Monitoring and managing insecticide resistance in Aedes mosquito populations. Interim guidance for entomologists. WHO/ZIKVNC/16.1. Geneva: World Health Organization; 2016.

32. Abbott W. A method of computing the effectiveness of an insecticide. J Econ Entomol. 1925:18:265-7.

33. Finney D. Probit Analysis. Cambridge: Cambridge University Press; 1971.

34. Marcombe S, Darriet F, Agnew P, Etienne M, Yp-Tcha M-M, Yebakima A, et al. Field efficacy of new larvicide products for control of multi-resistant Aedes aegypti populations in Martinique (French West Indies). Am J Trop Med Hyg. 2011;84:118-26.

35. Suter T, Crespo MM, de Oliveira MF, de Oliveira TSA, de Melo-Santos MAV, de Oliveira CMF, et al. Insecticide susceptibility of Aedes albopictus and Ae. aegypti from Brazil and the Swiss-Italian border region. Parasit Vectors. 2017;10:431.

36. Bellinato DF, Viana-Medeiros PF, Araújo SC, Martins AJ, Lima JBP, Valle D. Resistance status to the insecticides temephos, deltamethrin, and diflubenzuron in Brazilian Aedes aegypti populations. BioMed Res Int. 2016:2016:8603263.

37. Tetreau G, Chandor-Proust A, Faucon F, Stalinski R, Akhouayri I, Prud'homme $\mathrm{SM}$, et al. Contrasting patterns of tolerance between chemical and biological insecticides in mosquitoes exposed to UV-A. Aquat Toxicol. 2013; 140-141:389-97.

38. dos Santos Dias L, Macoris MLG, Andrighetti MTM, Otrera VCG, Dias AS, Bauzer LGSR, et al. Toxicity of spinosad to temephos-resistant Aedes aegypti populations in Brazil. PLoS One. 2017;12:e0173689.

39. Lau KW, Chen CD, Lee HL, Norma-Rashid Y, Sofian-Azirun M. Evaluation of insect growth regulators against field-collected Aedes aegypti and Aedes albopictus (Diptera: Culicidae) from Malaysia. J Med Entomol. 2015;52: 199-206.

40. Chen CD, Nazni WA, Lee HL, Sofian-Azirun M. Weekly variation on susceptibility status of Aedes mosquitoes against temephos in Selangor, Malaysia. Trop Biomed. 2005;22:195-206. 
41. Marcombe S, Farajollahi A, Healy SP, Clark GG, Fonseca DM. Insecticide resistance status of United States populations of Aedes albopictus and mechanisms involved. PLoS One. 2014;9:e101992.

42. Yunta C, Grisales N, Nász S, Hemmings K, Pignatelli P, Voice M, et al. Pyriproxyfen is metabolized by P450s associated with pyrethroid resistance in An. gambiae. Insect Biochem Mol Biol. 2016;78:50-7.

43. Hemingway J, Hawkes NJ, McCarroll L, Ranson H. The molecular basis of insecticide resistance in mosquitoes. Insect Biochem Mol Biol. 2004;34:653-65.

44. Moyes CL, Vontas J, Martins AJ, Ng LC, Koou SY, Dusfour I, et al. Contemporary status of insecticide resistance in the major Aedes vectors of arboviruses infecting humans. PLoS Negl Trop Dis. 2017;11:e0005625.

45. Poupardin R, Reynaud S, Strode C, Ranson H, Vontas J, David JP. Crossinduction of detoxification genes by environmental xenobiotics and insecticides in the mosquito Aedes aegypti: impact on larval tolerance to chemical insecticides. Insect Biochem Mol Biol. 2008;38:540-51.

46. Seccacini E, Lucia A, Harburguer L, Zerba E, Licastro S, Masuh H. Effectiveness of pyriproxyfen and diflubenzuron formulations as larvicides against Aedes aegypti. J Am Mosq Control Assoc. 2008;24:398-403.

47. Thavara U, Tawatsin A, Chansang C, Asavadachanukorn P. Simulated field evaluation of the efficacy of two formulations of diflubenzuron, a chitin synthesis inhibitor against larvae of Aedes aegypti (L.) (Diptera: Culicidae) in water-storage containers. Southeast Asian J Trop Med Public Health. 2007: 38:269-75.

48. Baldacchino F, Caputo B, Chandre F, Drago A, della Torre A, Montarsi F, et al. Control methods against invasive Aedes mosquitoes in Europe: a review. Pest Manag Sci. 2015;71:1471-85.

49. Mahilum MM, Ludwig M, Madon MB, Becker N. Evaluation of the present dengue situation and control strategies against Aedes aegypti in Cebu City, Philippines. J Vector Ecol. 2005;30:277-83.

50. Corriveau R, Philippon B, Yebakima A. La Dengue dans les Départements Français d'Amérique. Comment Optimiser la Lutte Contre Cette Maladie? IRD Édition. Paris: Expertise Collégiale; 2003.

51. Darriet F, Marcombe S, Etienne M, Yébakima A, Agnew P, Yp-Tcha M-M, et al. Field evaluation of pyriproxyfen and spinosad mixture for the control of insecticide resistant Aedes aegypti in Martinique (French West Indies). Parasit Vectors. 2010;3:88.

52. Ahmed MAI, Vogel CFA. The role of octopamine receptor agonists in the synergistic toxicity of certain insect growth regulators (IGRS) in controlling dengue vector Aedes aegypti (Diptera: Culicidae) mosquito. Acta Trop. 2016; 155:1-5

53. Becker N, Petric D, Zgomba M, Boase C, Dahl C, Lane J, Kaiser A. Mosquitoes and their Control. New York: Kluwer Academic/Plenum Publishers: 2003.

Ready to submit your research? Choose BMC and benefit from:

- fast, convenient online submission

- thorough peer review by experienced researchers in your field

- rapid publication on acceptance

- support for research data, including large and complex data types

- gold Open Access which fosters wider collaboration and increased citations

- maximum visibility for your research: over $100 \mathrm{M}$ website views per year

At $\mathrm{BMC}$, research is always in progress.

Learn more biomedcentral.com/submissions 